\title{
US nurse who contracted Ebola leaves hospital
}

\author{
Michael McCarthy \\ Seattle
}

One of the two US nurses who contracted Ebola virus disease while caring for a patient from west Africa in a hospital in Dallas, Texas, has been released from the high level bio-containment isolation unit at the National Institutes of Health's Clinical Center in Bethesda, Maryland.

Nina Pham, 26, of Fort Worth, Texas, became infected while taking care of Eric Thomas Duncan, a 42 year old Liberian national who fell ill shortly after he traveled from west Africa to Dallas in late September. Duncan was admitted to Texas Health Presbyterian Hospital Dallas 28 September. Despite intensive care, which included ventilator support and renal dialysis, Duncan died 8 October.

Pham had extensive contact with Duncan during the first days of his stay in hospital, when he was severely ill, and developed a low grade fever 10 October. She was admitted to Texas Health Presbyterian Hospital Dallas and was later transferred to the Bethesda Clinical Center.

Appearing at a press conference at the center 24 October, Pham, smiling and appearing fit, thanked the doctors and nurses who cared for her in Texas and at the center. "Throughout this ordeal I have put my trust in God and my medical team," Pham told reporters.

Pham later went to the White House where she was hugged by President Barack Obama. The president was "not at all concerned" about the risk of infection, White House press secretary Josh Earnest later told the press.

Anthony S Fauci, director of the National Institute of Allergy and Infectious Diseases, said that Pham had undergone five consecutive polymerase chain reaction tests that were unable to detect any remaining virus. "She has no virus in her," Fauci said.
While in hospital in Dallas, Pham received plasma from Kent Brantly, a physician who contracted the disease in July while treating patients with Ebola virus disease in Liberia, in the hope that the antibodies he acquired from his infection would help Pham clear the virus. Fauci said it was conceivable that the plasma infusion helped but that there was no way to prove it had.

Otherwise, Pham received only supportive care and was given none of the experimental treatments that have been administered to some of the other patients in the United States, Europe, and Africa, Fauci said.

Fauci said he could not explain how Pham recovered so quickly from a disease that has a $70 \%$ mortality rate in Africa but added that he thought that two factors played a role: "She's young and very healthy, number one. Number two: she got into a healthcare system that was able to give her intensive care early."

Fauci said, "She is an individual who is extraordinary. But she also represents the nurses and healthcare workers who put themselves on the line and put themselves at risk taking care of people who are in such need."

Amber Vinson, 29, the second nurse caring for Duncan who contracted Ebola virus disease, is being treated at Emory University Hospital in Atlanta, Georgia, which also has high level isolation units. Tests no longer detect the virus in her blood, and she is "making good progress," the hospital said, but she will remain in the hospital for supportive care, and there are currently no plans for discharging her.

Cite this as: BMJ 2014;349:g6468

๑) BMJ Publishing Group Ltd 2014 